Method Article

\title{
Elaborating a systems methodology for cascading climate change impacts and implications
}

\author{
Nicholas A. Cradock-Henry ${ }^{\mathrm{a}, *}$, Justin Connolly ${ }^{\mathrm{b}}$, Paula Blackett ${ }^{\mathrm{c}}$, \\ Judy Lawrence ${ }^{\mathrm{d}}$ \\ a Manaaki Whenua - Landcare Research, Lincoln, New Zealand \\ ${ }^{\mathrm{b}}$ Deliberate Consulting, Hamilton, New Zealand \\ ${ }^{\mathrm{C}}$ National Institute of Water and Atmosphere, Hamilton, New Zealand \\ ${ }^{\mathrm{d}}$ Victoria University of Wellington, Wellington, New Zealand
}

\section{A B S T R A C T}

New research is drawing attention to the potential for climate change to generate cascading impacts and implications across linked human-environment systems, requiring closer accounting of these interactions to anticipate the emergence of surprises and feedbacks. However, there is little practical guidance for those interested in characterising, identifying or assessing cascades, and few empirical examples. In this paper, we elaborate a systems-based methodology to identify and evaluate cascading climate change impacts and implications. We illustrate its application using the case of a participatory process with urban infrastructure managers, facing the legacy effects of damaging earthquakes and the prospect of future climate change. The results show the proposed approach and visualisation of cascades as causal diagrams provides a robust and flexible analytical framework. The use of systems thinking, visual aids, interactive discussion and expert elicitation generated valuable information about potential cascades, their interactions across domains of interest, and the implications for management. The process can provide a basis for further empirical application and advance methodological and conceptual development.

Specifically, the systems methodology:

- Identifies interdependencies and interconnections which may serve as transmission pathways for climaterelated impacts;

- Enhanced stakeholders' understanding of multiple causes and effects of climate change; and

- Produced a useful visual aid for stakeholders to explore cascading impacts and implications, and opportunities for intervention.

(C) 2020 The Author(s). Published by Elsevier B.V. This is an open access article under the CC BY license. (http://creativecommons.org/licenses/by/4.0/)

\footnotetext{
* Corresponding author.

E-mail address: cradockhenryn@landcareresearch.co.nz (N.A. Cradock-Henry).
} 
A R T I C L E I N F O

Method name: Systems methodology for cascading climate change impacts and implications

Keywords: Climate change adaptation, Vulnerability, Systems thinking, Feedback, Complex problems

Article history: Received 5 March 2020; Accepted 3 April 2020; Available online 19 April 2020

\section{Specifications table}

\begin{tabular}{ll}
\hline Subject Area: & Environmental Science \\
& Natural resource management \\
More specific subject area: & Climate change impacts \\
Method name: & Systems methodology for cascading climate change impacts and implications \\
Name and reference of original & Lawrence J, Blackett P, Cradock-Henry NA. Cascading Climate Change Impacts and \\
method: & Implications. Climate Risk Management. CLRM_2019_163 \\
Resource availability: & N/A \\
\hline
\end{tabular}

\section{Method details}

\section{Background}

There is increasing evidence of the effects of climate change on linked human-environment, or social-ecological systems $[5,6,15,16]$. The consequences of higher mean temperatures, increasing climate variability and more frequent extremes, are evidenced in the dramatic rise in weather-related losses over the last decade, placing additional pressure on already marginalised systems, communities and locations [14,19,40,51]. Furthermore, the felt impacts of climate change do not happen in isolation [43]. While increased rainfall can result, for example, in higher rates of soil erosion, increased flooding and landslides, they can have implications across and between multiple domains [31,32]. The interaction and feedback between local environments (such as steep hillsides), downstream receiving catchments and tributaries, and flood protection measures, are only just beginning to be recognised in the literature [39]. At a global level, Anthropocene risk - emerging from the interactions between multiple processes - has implications for management, and requires cross-scale interventions [30].

The potential for climate change impacts and implications to 'cascade' across and between multiple domains, is prompting new research aimed at conceptualising and empirically examining their combined effects in diverse settings $[9,18,23,32,42]$. While the cascade effect has been studied elsewhere - most notably in disaster risk research [2,3], and studies of networked infrastructure and lifelines $[17,20,29]$ - there are few empirical examples from climate change research, and limited practical guidance for researchers, policy makers and practitioners in how cascades might be identified, characterised and considered as part of planning and management.

The 'Cascading Climate Change Impacts and Implications' (CCCII) project in Aotearoa-New Zealand (New Zealand) was one of the first studies to develop and apply a conceptual and methodological approach to cascades in the context of climate change [34,58]). In it, we explore the implications of cascades to help focus adaptation interventions and enhance resilience. In this paper, we extend the exploration of cascades in the context of climate change and elaborate on the five-step process used that is based on the theory and practice of systems thinking. Systems thinking is a scientific methodology and set of tools that deal with complexity, ambiguity and mental models [27,35]. Importantly, systems thinking focuses on the whole system as well as the constituent parts and their interactions. It therefore provides a framework for managing change and complexity, through the understanding of dynamic feedback embedded in complex systems [27].

In the climate change context, systems thinking allows decision makers to anticipate the longterm consequences of their decisions and actions, by considering the interdependencies between them, as well as the unintended consequences of policies and strategies [4]. As such it can support comprehensive and robust adaptation planning, reducing the risk of maladaptation and a narrow focus on a single problem [57]. Overall, systems thinking provides a collective understanding of how 
a systems functions and a common language for diverse stakeholders to enable deep dialogue and consensus building $[35,37,46]$.

\section{Method details}

In the literature on climate change impacts assessment, a number of different methods have been advanced in recent years, from probabilistic, model-based scenarios of future change, to in-depth participatory assessments based on rich qualitative insights from stakeholders. Increasingly however, there is a call for more integrated approaches to impacts assessment that combine both top-down and bottom-up perspectives, to gain insight into the diverse contexts for adaptation. Many of these integrated approaches use elements of systems thinking $[10,46,55]$ applying it to a wide range of topics related to climate change impacts, implications and adaptation [21,26,32,36,45]. By providing a formalised and accepted language for articulating relationships, synergies and trade-offs - systemsbased approaches enable integrative and holistic assessments, incorporating multiple dimensions of sustainability $[21,41,46,56]$. Furthermore, there is increasing evidence for a 'participatory' turn in impacts assessment, and greater emphasis on both scientific and lay knowledge, to enhance the relevance, credibility and legitimacy of assessments to improve the likelihood of having a positive effect on desired outcomes $[7,8,14,22,44,46]$.

Cascading climate change impacts and implications are inherently complex and contested problems [9,32], with significant uncertainties and evolving complexities. As such, it is ill-suited to investigation using the traditional scientific method which relies on systematic experimentation which can be validated - and its credibility enhanced - through repetition [8]. For complex problems such as this, there are multiple stakeholders involved, with diverse perspectives and assumptions, undertaking different actions towards possible solutions [48], requiring a different approach. To overcome the difficulties of establishing the credibility of learning outcomes from this type of enquiry, it has been suggested that the method of enquiry and area of concern, should be declared in advance, creating an intellectual structure to reflect upon research outcomes $[11,24,48]$. Clearly stating theoretical ideas, research themes and a clear statement of the methods makes it easier for others to recover the research process and evaluate findings [11]. Without it, results of investigation may be perceived as anecdotal accounts of an interesting case, limiting opportunities to comparison and sharing $[1,11]$.

We use system dynamics as a "declared in advance" methodology [11]. The process as outlined here, is intended to enable others to critique the process, and further apply and refine it, to meet the criteria for recoverability [11]. The process is informed by established systems-based methodologies and group model building to gain insight into the cascading impacts and implications of climate change. The steps we followed were used to focus dialogue in stakeholder workshops on how different climate change risks (e.g. extreme rainfall events) resulted in impacts that were transmitted to other sectors, activities or domains [34].

While the choice of methods may vary, assessments typically include problem identification, system description (and any normative outcomes desired), assessment of impacts, identification of options, followed by implementation and evaluation. For this project we developed a simplified impacts assessment focused on cascades using a methodology that combined systems thinking with a participatory approach, grounded in stakeholders' understandings and perceptions, to characterise cascading climate change impacts and implications [34]. We used a five-step process as follows:

1. Problem definition

2. Mapping critical infrastructure

3. Generate narratives of cascading impacts and implications

4. Develop system map

5. Evaluate and refine

The stepwise framework is aimed at generating evidence to enhance understanding of the scale and scope of cascading climate change impacts, particularly with a focus on critical local infrastructure. The application of the framework can be used to identify key interdependencies, 
feedbacks and co-dependencies, and determine how impacts and implications might extend across multiple sectors.

\section{Problem definition}

The first step in the process was to articulate the problem and better understand stakeholders' perceptions of the issue. In systems thinking, boundaries are flexible and can be set at a scale that is appropriate to the question of interest. In this case, boundaries were drawn to include factors that influenced the function of infrastructure, where infrastructure was broadly defined as three waters (wastewater, stormwater, and water supply services provided by local government in New Zealand), flood and inundation protection structures, utilities, and road networks.

Stakeholder workshops were used to develop a shared view of the system of interest - including the interaction of roles and responsibilities, norms and the political and decision-making context. A simple scenario of changes in key climate change variables (i.e. precipitation, temperature, and frequency and variability of extremes and how emergent impacts propagate) was used to prompt initial discussions exploring the impacts of climate change on a selected domain (e.g. urban water infrastructure). Structured questions and activities solicited information about the issue and affected systems.

Questions used for defining the problem included:

- What is the system of concern? (set the boundaries of the system)

- How would you describe the current system?

- What are the effects of climate change on the system and its management?

- slowly emerging impacts, e.g. sea level rise, plant and animal diseases

- widening climate variability, e.g. drought, increased flood frequency

- extremes, e.g. coastal storm surge, intense rainfall, wind

- What are the implications for decision making inside and outside the system?

The resulting information was used to develop a problem statement and a 'rich picture' of the current situation and of stakeholders' views of the problem [38,50]. Problem statements should typically include both the problem context and an agreed version of problem to be addressed. Our problem statement is as follows:

Local government decision-makers would benefit from having the ability to understand the cascading impacts of climate on critical infrastructure. Ideally this would help decision-makers understand how these impacts would flow on to other elements of the various complex socioecological systems that such critical infrastructure supports.

\section{Mapping critical infrastructure}

This step was used to establish a conceptual and empirical basis for system model development. At its most fundamental level an infrastructure system performs a variety of functions for society, including services to the public, often without them even realising, that enable society to operate to an expected level. Workshop dialogue was used in conjunction with the CIrcle Tool (Critical Infrastructures: Relations and Consequences for Life and Environment) - an interactive mapping tool - to identify services that may be affected by climate change, and their interdependencies [25].

Participants identified critical infrastructure within the geographical area of interest and considered both how climate change (i.e. slowing emerging impacts, widening climate variability and extremes) might affect that infrastructure and how the different infrastructure types were connected with each other, and with other social and economic components of the system. Components included groundwater, governance, water supply, financial services, healthcare and more (Fig. 1).

Workshop discussions were used to identify the number of times each input category interconnected with another in the system. These critical nodes indicated potential priority areas for decision makers' attention, and helped establish critical dependencies with widespread consequences. For example, rising sea levels and/or more extreme rainfall events are interconnected to outcomes in 


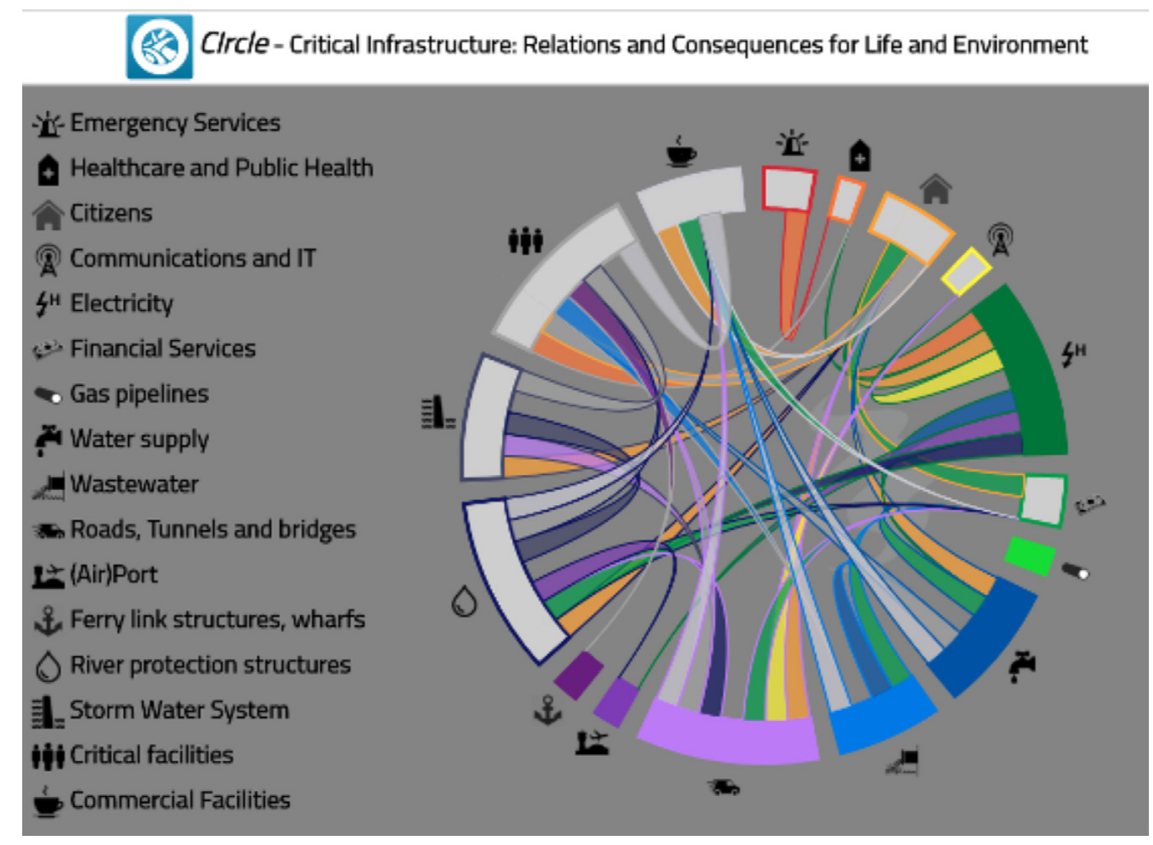

Fig. 1. (Appx. here) Example of CIrcle derived dependencies between impact categories described by workshop participants.

other parts of the system. The resulting floods, for example, may impede road access and contaminate streams. Health and community well-being are also affected by damp in homes, and limiting access to social infrastructure such as schools and hospitals [34].

The aim was to conceptualize activities relevant to the problem situation. The output was used to inform the building blocks of potential cascades and a system map by describing how parts of the system were understood to be connected. Visually displaying the connections between infrastructure components in real time, during the workshop, provided an opportunity to iterate system representation, and discuss amongst each other, the significance of interdependencies, helping stakeholders understand the complex and interdependent relations between critical infrastructure systems.

\section{Narratives of cascading impacts and implications}

In other studies, using system dynamics and development of systems diagrams, often begins with the use of simple, familiar models (e.g. maps, visualisations, tables and lists). For this step, information from workshop participants, media stories about impacts of recent storm events and the authors' previous research on climate change impacts and implications [33] was used to develop narratives of cascading impacts [34].

Narratives are used here to refer to plausible storylines of cascading impacts and implications. Stories are increasingly used to communicate information on climate change, and can provide important tools to support decision-making and strategic planning $[13,28]$. The narratives elaborated on cascading systems loops, using locally-relevant examples, in some cases informed by recent events. Using examples described in media, such as flood events or other disruptions, enhanced the relevance of narratives and helped decision makers consider implications of cascades, which might otherwise be framed as discrete impacts in place and time. 
The workshop participants provided information about the variables, interconnections and feedbacks for each domain of interest (e.g. for urban water infrastructure, flood protection and lifelines infrastructure). Maps were used to focus dialogue on the local context, and information was abstracted to develop accessible narratives to inform a generalised system model to better describe interactions.

\section{Develop systems map}

The underlying presumption in systems dynamics is of inter-connectedness and the natural integration of biophysical, physical, cultural, social, political, organisational, and economic elements that enable co-construction of systems to explore and explain what is observed in the real world. The relationships between the factors in the system have a direction: 'A is related to B' to, for example, 'as A increases B decreases', which enables identification of reinforcing or balancing loops within the system. Accordingly, vicious or virtuous cycles can be exposed (reinforcing loops) as well as where relationships have a 'cancelling-out' effect (balancing loops). For additional detail and discussion of systems maps, see Supplementary Materials.

To further explore these dynamics, we used Vensim modelling software (Ventanna Systems, Inc.) to create a systems map that represented the causal relationships described by participant stakeholders (Fig. 2). The systems map (also known as a causal loop diagram, since it shows dependencies and interdependencies) shows how the different types of climate change impacts (e.g., extreme events and slowly emerging impacts) have similar interdependencies, feedback loops, and generate similar cascades across other domains. This allows for the consideration of these characteristics at a more generic conceptual scale. The systems map highlights relations, or causal links, between infrastructure systems, and can be used to analyse and visualize cascading impacts and implications elsewhere. Individual cascades relating to particular infrastructure were aggregated into a single system map, because it was evident that strong commonality existed between how the individual systems operated. As a result, the map represents all types of infrastructure for all the climate impacts considered.

Once the system was described and drawn, we considered how it may be affected by climate change (i.e., slowly emerging, widening climate variability, or extreme events) or specific policy intervention to address those impacts - where interventions are deliberate actions to achieve a desired change(s). The implications of changes or interventions were traced through the system and examined for any unintended consequences. Potential cascades were then discussed and recorded.

Initially two versions of the systems map were developed: one high-level, containing 13 factors; and a second detailed one, containing 59 factors ( 4 times more complex based on the number of factors). Participants were more comfortable with the detailed version of the map (Fig. 2).

\section{Evaluate and refine}

Once constructed, the systems map was tested with a sub-set of key informants in a small workshop and in one-on-one meetings. Structured dialogue was used to step through the systems map, focusing first on the four sub-systems (infrastructure, community, and funding and financial services) and then the causal relations between them [58]. The aim was to ensure the systems map captured their perspective of how the system functioned. Providing an opportunity for reflection on the systems map, and discussing how stakeholders might usefully use it in their own work, also contributed to enhancing the relevance and legitimacy of findings [8]. Minor amendments were made based on stakeholder feedback, and a final system map was produced.

The systems maps shows complex and interdependent cascades linked by seven feedback loops across four sub-areas of the system. Importantly, the systems map illustrates how the cascades arise from a climate change impact and move across space and organizations, affecting ecological, social, and economic domains. The cascades can move through a connected social-ecological system, combining or exacerbating the impacts, because of external policy decisions or concurrent impacts or events. While the three climate-derived impacts of concern (high-intensity rainfall events, sealevel rise and drought) can be characterised for the purposes of building cascades, it is important to remember that the different types of impacts can occur simultaneously at the same geographical 


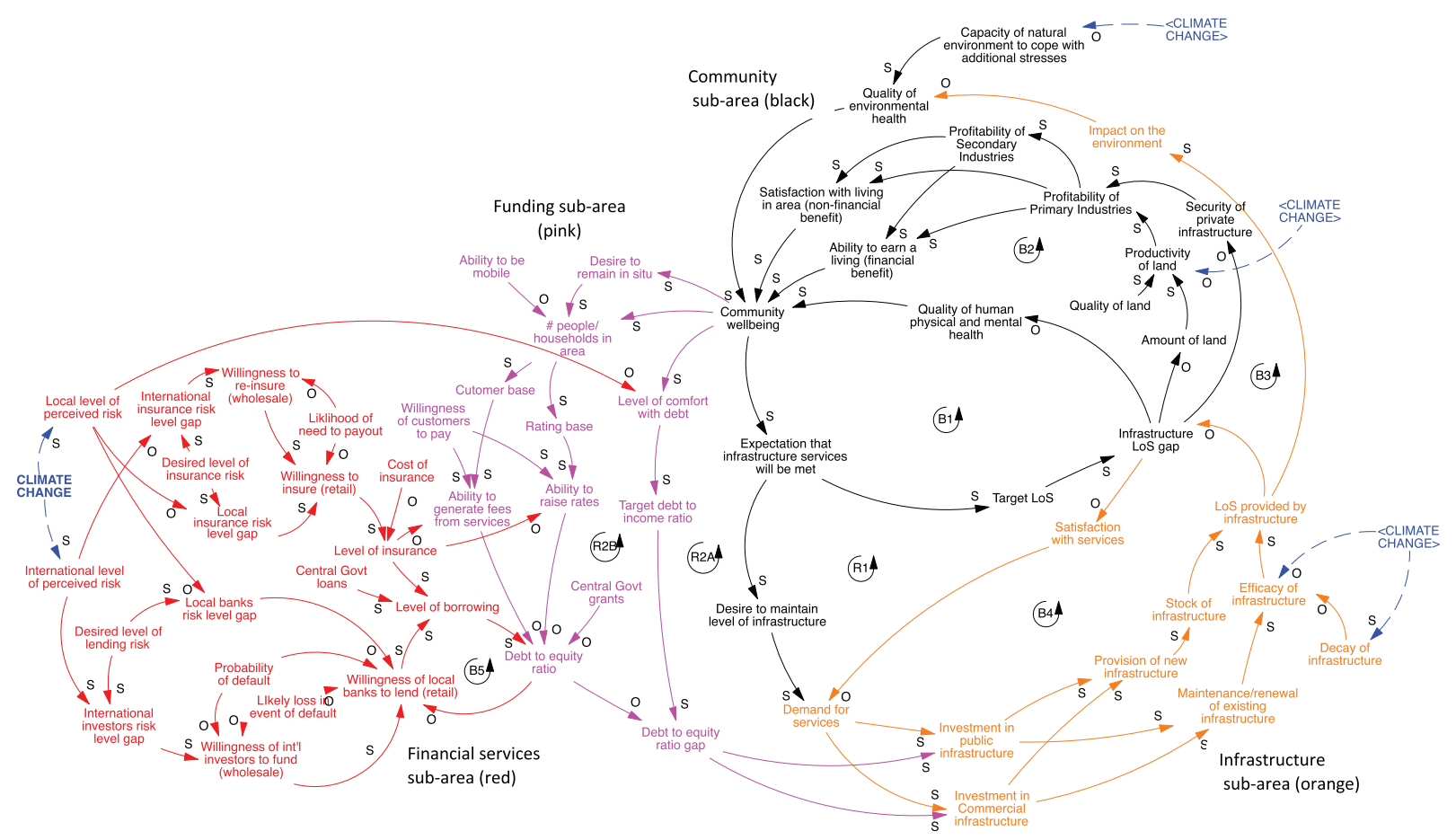

Fig. 2. (Appx. here) Systems map showing cascading impacts across multiple domains. 
location. This could create multiple simultaneous cascades that recombine in potentially unpredictable ways or accelerate movement towards a threshold. The incidence of surprises cannot be characterised by definition but cannot be ruled out as further stressors on the systems.

The seven feedback loops and dependencies are the critical elements of the systems mapping process. The systems map presented here (Fig. 2) is a summary of the overall system of four subareas of the systems (community - black; infrastructure - orange; funding - purple; financial risk red) and factors driving the cascades in each domain.

\section{Method validation}

The participatory process, which involved multiple stakeholders with diverse perspectives derived from their disciplinary and functional responsibilities in each of the domains, was able to motivate insights into the complexity of interdependencies, and enabled joint learning [34]. This and other examples of group model building [54] with policy-makers and managers have been shown to enhance understanding of system dynamics, causal relations and the effects of decisions in other contexts $[12,47,52-54]$.

Workshop participants described the use of systems dynamics and model development as highly beneficial for thinking about the wider implications of climate change impacts. In particular, more subjective links and causal relationships (e.g. Community wellbeing; Perceived level of risk (in relation to climate impacts); Willingness to insure), that are not included in probabilistic or economic models were incorporated in the systems map, providing a richer picture of the complexities of the system. As such, the systems map was effective at making multiple interconnections and interdependencies within the system, explicit, demonstrating the emergence of the cascading phenomena [34]. For example; the circular nature of the relationship between community wellbeing and infrastructure was insightful, as was the observation that increasing levels of infrastructure will, over time, gradually increase the expectations for even greater levels of infrastructure - continually adding upward pressure to community expectations. Another important insight was the significant influence of finance and insurance on the ability to invest in new or for maintaining existing infrastructure.

The systems map also demonstrated the multiple pathways of causality that climate change impacts have on other variables within the wider system. This highlighted that a changing climate will affect the system at several points and may combine or compound the impacts, because of external policy decisions or concurrent impacts or events.

The explicit labelling of feedback loops in the system map also provided insights on the presence of balancing or reinforcing loops. While the majority of the map is made up of balancing loops, several potentially vicious loops were identified. One example of this is the reinforcing loops relating to infrastructure funding - either through rates (taxes) or direct payment for services. When financial and community wellbeing are high, there is a corresponding capacity to rate or pay for infrastructure, positively reinforcing improved financial and community wellbeing. If the performance or level of infrastructure is sufficiently disrupted though, this loop could 'flip' into a negatively loop - with low financial and community wellbeing resulting in a reduced ability to rate or pay for infrastructure. The presence of reinforcing loops also provided a means to consider the governance implications of actions within the system [49], as well as any unintended consequences. Systems mapping is agnostic to organisational boundaries (internal or external) and the open discussion provided a forum for participants to better understand of how actions in one governance domain may impact (or be impacted by) other domains.

A key tension when applying systems thinking to a particular context is between too much, or too little detail to apply when generating the variables. Domain experts such as policymakers and managers, typically have detailed knowledge about their area of responsibility, but in this case, there was a need to consider multiple domains, requiring significant aggregation. Ultimately, the level of detail presented in the final map will be determined by how comfortable the participants are that their system domain is sufficiently represented to enable exploration and deliberation. 


\section{Conclusions and future research directions}

This paper has described an application of system mapping (based on System Dynamics causalloop diagramming) to explore the cascading impacts of climate change. A mixed methods approach was used, drawing on group model building using workshops and interviews, to elicit insights on the impacts of climate change from a range of participants with functions and experience in urban infrastructure and asset management, flood risk management, financial services. This information was collated by researchers into a systems map that synthesised the inter-relationships among the domains. This provided insights on how the impacts of climate change in one domain could cascade into other domains and how domains were interdependent creating circular (and repeating) cascades.

The systems methodology elicited interdependencies and interconnections (especially with finance and insurance) and it enabled an understanding of multiple causes and effects. Furthermore, it enabled exploration of the influence of different scales; exposure of vicious cycles in the system; and investigation and understanding of the governance implications of domain impacts and actions, within and between systems [34].

More detailed applications of this methodology in an area nested within the wider system would add to the knowledge of particular domains. For example, further exploration of the impact of perceived climate risk within the finance and insurance industries and its potential impact on the provision of infrastructure would contribute to investments in long-lived assets on which communities rely. The impact that this methodology had on the mental models of workshop participants remains untested and could be explored further. Finally, future research could also develop small-scale simulation models of the dynamics described in these (or any future maps), to test the narratives shown in the systems map for their ability to reflect the interactions and their implications in a changing climate.

\section{Declaration of Competing Interest}

The authors declare that they have no known competing financial interests or personal relationships that could have appeared to influence the work reported in this paper.

\section{Acknowledgments}

The authors were funded by the Deep South National Science Challenge Cascading climate change impacts in Aotearoa-New Zealand project. MBIE Contract \# CO1 × 1412. The authors thank all research participants for their contributions.

\section{Supplementary materials}

Supplementary material associated with this article can be found, in the online version, at doi: 10.1016/j.mex.2020.100893.

\section{References}

[1] C. Adler, G.H. Hadorn, T. Breu, U. Wiesmann, C. Pohl, Conceptualizing the transfer of knowledge across cases in transdisciplinary research, Sustain Sci. 13 (2017) 179-190, doi:10.1007/s11625-017-0444-2.

[2] A. AghaKouchak, L.S. Huning, F. Chiang, M. Sadegh, F. Vahedifard, O. Mazdiyasni, H. Moftakhari, I. Mallakpour, How do natural hazards cascade to cause disasters? Nature 561 (2018) 458, doi:10.1038/d41586-018-06783-6.

[3] D. Alexander, A magnitude scale for cascading disasters, Int. J. Disaster Risk Reduct. Understand. Mitigat. Cascad. Crises Global Interconn. Syst. 30 (2018) 180-185, doi:10.1016/j.ijdrr.2018.03.006.

[4] J.M. Anderies, M.A. Janssen, Robustness of social-ecological systems: implications for public policy, Policy Stud. J. 41 (2013) 513-536, doi:10.1111/psj.12027.

[5] N.W. Arnell, B. Lloyd-Hughes, The global-scale impacts of climate change on water resources and flooding under new climate and socio-economic scenarios, Climatic Change 122 (2014) 127-140, doi:10.1007/s10584-013-0948-4.

[6] A.G.E. Ausseil, A.J. Daigneault, B. Frame, E.I. Teixeira, Towards an integrated assessment of climate and socio-economic change impacts and implications in New Zealand, Environ. Modell. Softw. 119 (2019) 1-20, doi:10.1016/j.envsoft.2019.05. 009. 
[7] N.J. Bennett, A. Kadfak, P. Dearden, Community-based scenario planning: a process for vulnerability analysis and adaptation planning to social-ecological change in coastal communities, Environ. Dev. Sust. 18 (2016) 1771-1799, doi:10.1007/ s10668-015-9707-1.

[8] D.W. Cash, W.C. Clark, F. Alcock, N.M. Dickson, N. Eckley, D.H. Guston, J. Jäger, R.B. Mitchell, Knowledge systems for sustainable development, PNAS 100 (2003) 8086-8091, doi:10.1073/pnas.1231332100.

[9] A.J. Challinor, W.N. Adger, T.G. Benton, D. Conway, M. Joshi, D. Frame, Transmission of climate risks across sectors and borders, Phil. Trans. R. Soc. A 376 (2018) 20170301, doi:10.1098/rsta.2017.0301.

[10] E.J.L. Chappin, T. van der Lei, Adaptation of interconnected infrastructures to climate change: a socio-technical systems perspective, Utilities Policy 31 (2014) 10-17, doi:10.1016/j.jup.2014.07.003.

[11] P. Checkland, S. Holwell, Action research, in: N. Kock (Ed.), Information Systems Action Research: An Applied View of Emerging Concepts and Methods, Integrated Series in Information Systems, Springer US, Boston, MA, 2007, pp. 3-17, doi:10. 1007/978-0-387-36060-7_1.

[12] N. Ciobanu, A.K. Saysel, Using social-ecological inventory and group model building for resilience assessment to climate change in a network governance setting: a case study from Ikel watershed in Moldova, Environ Dev. Sustain (2020), doi:10. 1007/s10668-020-00590-8.

[13] L. Coulter, S. Serrao-Neumann, E. Coiacetto, Climate change adaptation narratives: linking climate knowledge and future thinking, Futures 111 (2019) 57-70, doi:10.1016/j.futures.2019.05.004.

[14] N.A. Cradock-Henry, P. Blackett, M. Hall, P. Johnstone, E. Teixeira, A. Wreford, Climate adaptation pathways for agriculture: insights from a participatory process, Environ. Sci .Policy 107 (2020) 66-79, doi:10.1016/j.envsci.2020.02.020.

[15] S.L. Cutter, A. Ismail-Zadeh, I. Alcántara-Ayala, O. Altan, D.N. Baker, S. Briceño, H. Gupta, A. Holloway, D. Johnston, G.A. McBean, Y. Ogawa, D. Paton, E. Porio, R.K. Silbereisen, K. Takeuchi, G.B. Valsecchi, C. Vogel, G. Wu, Global risks: pool knowledge to stem losses from disasters, Nature 522 (2015) 277-279, doi:10.1038/522277a.

[16] A. Fekete, P. Sakdapolrak, Loss and damage as an alternative to resilience and vulnerability? preliminary reflections on an emerging climate change adaptation discourse, Int. J. Disaster Risk Sci. 5 (2014) 88-93, doi:10.1007/s13753-014-0012-7.

[17] Y. Feng, L. Xiang-Yang, Improving emergency response to cascading disasters: applying case-based reasoning towards urban critical infrastructure, Int. J. Disaster Risk Reduct. Understand. Mitigat. Cascading Crises Global Interconnect. Syst. 30 (2018) 244-256, doi:10.1016/j.ijdrr.2018.04.012.

[18] V. Galaz, F. Moberg, E.-K. Olsson, E. Paglia, C. Parker, Institutional and political leadership dimensions of cascading ecological crises, Publ. Adm. 89 (2011) 361-380, doi:10.1111/j.1467-9299.2010.01883.x.

[19] M. Gall, K.A. Borden, C.T. Emrich, S.L. Cutter, The unsustainable trend of natural hazard losses in the United States, Sustainability 3 (2011) 2157-2181, doi:10.3390/su3112157.

[20] J.C. Gill, B.D. Malamud, Hazard interactions and interaction networks (cascades) within multi-hazard methodologies, Earth Syst. Dyn. 7 (2016) 659-679, doi:10.5194/esd-7-659-2016.

[21] R. Gillard, A. Gouldson, J. Paavola, J.V. Alstine, Transformational responses to climate change: beyond a systems perspective of social change in mitigation and adaptation, Wiley Interdiscipl. Rev. Climate Change 7 (2016) 251-265, doi:10.1002/wcc. 384.

[22] L. Gouttenoire, S. Cournut, S. Ingrand, Participatory modelling with farmer groups to help them redesign their livestock farming systems, Agron. Sustain. Dev. 33 (2013) 413-424, doi:10.1007/s13593-012-0112-y.

[23] G. Hilly, Z. Vojinovic, S. Weesakul, A. Sanchez, D.N. Hoang, S. Djordjevic, A.S. Chen, B. Evans, Methodological Framework for Analysing Cascading Effects from Flood Events: The Case of Sukhumvit Area, Water, Bangkok, Thailand, 2018 10, 81 , doi: $10.3390 / \mathrm{w} 10010081$.

[24] A.-I. Horcea-Milcu, B. Martín-López, D. Lam, D. Lang, Research pathways to foster transformation: linking sustainability science and social-ecological systems research, Ecol. Soc. 25 (2020), doi:10.5751/ES-11332-250113.

[25] M.w.a. Hounjet, A.t.m.m. Kieftenburg, M. Altamirano, Learning from flood events on critical infrastructure: relations and consequences for life and environment (Clrcle), in: Proceedings of the Coastal Management, Conference Proceedings, ICE Publishing, 2016, pp. 407-413, doi:10.1680/cm.61149.407.

[26] E. Irwin, J. Campbell, R. Wilson, A. Faggian, R. Moore, N. Irwin, Human adaptations in food, energy, and water systems, J. Environ Stud. Sci. 6 (2016) 127-139, doi:10.1007/s13412-016-0375-8.

[27] R.L. Ison, Systems Practice: How to Act in a Climate Change World, Springer, Berlin, 2010.

[28] M.D. Jones, D.A. Crow, How can we use the 'science of stories' to produce persuasive scientific stories? Palgrave Commun. 3 (2017) 1-9, doi:10.1057/s41599-017-0047-7.

[29] H. Kachali, I. Storsjö, I. Haavisto, G. Kovács, Inter-sectoral preparedness and mitigation for networked risks and cascading effects, Int. J. Disaster Risk Reducti. Understand. Mitigat. Cascad. Crises Global Interconnect. Syst. 30 (2018) 281-291, doi:10. 1016/j.ijdrr.2018.01.029.

[30] P.W. Keys, V. Galaz, M. Dyer, N. Matthews, C. Folke, M. Nyström, S.E. Cornell, Anthropocene risk, Nat. Sustain 2 (2019) 667-673, doi:10.1038/s41893-019-0327-x.

[31] A. Kinzig, P. Ryan, M. Etienne, H. Allison, T. Elmqvist, B. Walker, Resilience and regime shifts: assessing cascading effects, Ecol. Soc. 11 (2006).

[32] E. Koks, Moving flood risk modelling forwards, Nat. Clim. Chang. 8 (2018) 561-562, doi:10.1038/s41558-018-0185-y.

[33] Lawrence, J., Blackett, P., Cradock-Henry, N., Flood, S., Greenaway, A., Dunningham, A., 2016. Synthesis Report RA4: Enhancing capacity and increasing coordination to support decision making. Climate Change Impacts and Implications (CCII) for New Zealand to 2100. MBIE contract C01X1225.

[34] J. Lawrence, P. Blackett, N.A. Cradock-Henry, Cascading climate change impacts and implications, Climate Risk Manag. (2020) (in review).

[35] K.E. Maani, R.Y. Cavana, Systems Thinking, System Dynamics, 2 ed., Pearson Education Canada, Rosedale, 2007.

[36] Y.T. Maru, M. Stafford Smith, A. Sparrow, P.F. Pinho, O.P. Dube, A linked vulnerability and resilience framework for adaptation pathways in remote disadvantaged communities, Global Environ. Change 28 (2014) 337-350, doi:10.1016/j. gloenvcha.2013.12.007.

[37] L. Merwe, R. Biggs, R. Preiser, Building social resilience in socio-technical systems through a participatory and formative resilience approach, Systemic Change J. (2019) 1-34. 
[38] A. Monk, S. Howard, Methods \& tools: the rich picture: a tool for reasoning about work context, Interactions 5 (1998) 21-30, doi:10.1145/274430.274434.

[39] G. Oulahen, G. McBean, D. Shrubsole, S.E. Chang, Production of risk: multiple interacting exposures and unequal vulnerability in coastal communities, Reg. Environ. Change. (2018), doi:10.1007/s10113-018-1440-5.

[40] P.N. Peregrine, Social resilience to climate-related disasters in ancient societies: a test of two hypotheses, Weather Climate Soc. 10 (2018) 145-161, doi:10.1175/WCAS-d-17-0052.1.

[41] G. Pescaroli, D. Alexander, Critical infrastructure, panarchies and the vulnerability paths of cascading disasters, Nat Hazards 82 (2016) 175-192, doi:10.1007/s11069-016-2186-3.

[42] G. Pescaroli, M. Nones, L. Galbusera, D. Alexander, Understanding and mitigating cascading crises in the global interconnected system, Int. J. Disaster Risk Reduct. 30 (2018) 159-163, doi:10.1016/j.ijdrr.2018.07.004.

[43] A. Räsänen, S. Juhola, A. Nygren, M. Käkönen, M. Kallio, A.M. Monge, M. Kanninen, Climate change, multiple stressors and human vulnerability: a systematic review, Reg. Environ. Change 16 (2016) 2291-2302, doi:10.1007/s10113-016-0974-7.

[44] C. Raudsepp-Hearne, G.D. Peterson, E.M. Bennett, R. Biggs, A.V. Norström, L. Pereira, J. Vervoort, D.M. Iwaniec, T. McPhearson, P. Olsson, T. Hichert, M. Falardeau, A.J. Aceituno, Seeds of good anthropocenes: developing sustainability scenarios for Northern Europe, Sustain Sci. (2019), doi:10.1007/s11625-019-00714-8.

[45] D. Rodriguez, P. deVoil, B. Power, H. Cox, S. Crimp, H. Meinke, The intrinsic plasticity of farm businesses and their resilience to change. An Australian example, Field Crops Res. 124 (2011) 157-170, doi:10.1016/j.fcr.2011.02.012.

[46] H. Ross, S. Shaw, D. Rissik, N. Cliffe, S. Chapman, V. Hounsell, J. Udy, N.T. Trinh, J. Schoeman, A participatory systems approach to understanding climate adaptation needs, Climatic Change 129 (2015) 27-42, doi:10.1007/s10584-014-1318-6.

[47] R.J. Scott, R.Y. Cavana, D. Cameron, Recent evidence on the effectiveness of group model building, Eur. J. Oper. Res. 249 (2016) 908-918, doi:10.1016/j.ejor.2015.06.078.

[48] J. Sendzimir, P. Magnuszewski, Z. Flachner, P. Balogh, G. Molnar, A. Sarvari, Z. Nagy, Assessing the resilience of a river management regime: informal learning in a shadow network in the Tisza river basin, Ecol. Soc. 13 (2008), doi:10.5751/ ES-02239-130111.

[49] P.M. Senge, The Fifth Discipline: The Art and Practice of the Learning Organization, 2nd ed., Doubleday, New York, NY, 2006.

[50] M.I. Shongwe, A systems thinking approach to investigating complex sugarcane supply and processing systems: integrating rich pictures and Bayesian networks, Syst. Pract. Action Res. 31 (2018) 75-85, doi:10.1007/s11213-017-9418-7.

[51] T. Tanner, D. Lewis, D. Wrathall, R. Bronen, N. Cradock-Henry, S. Huq, C. Lawless, R. Nawrotzki, V. Prasad, M.A. Rahman, R. Alaniz, K. King, K. McNamara, M. Nadiruzzaman, S. Henly-Shepard, F. Thomalla, Livelihood resilience in the face of climate change, Nature Clim. Change 5 (2015) 23-26, doi:10.1038/nclimate2431.

[52] B.L. Turner, H.M. Menendez, R. Gates, L.O. Tedeschi, A.S. Atzori, System dynamics modeling for agricultural and natural resource management issues: review of some past cases and forecasting future roles, Resources 5 (2016) 40, doi:10.3390/ resources5040040.

[53] M. van den Belt, Mediated Modeling: A System Dynamics Approach To Environmental Consensus Building, Island Press, 2004.

[54] J.A.M. Vennix, Group model-building: tackling messy problems, Syst. Dyn. Rev. 15 (1999) 379-401.

[55] B.H. Walker, N. Abel, J.M. Anderies, P. Ryan, Resilience, adaptability, and transformability in the Goulburn-Broken Catchment, Australia, Ecol. Soc. 14 (2009) 12.

[56] A. Williams, S. Kennedy, F. Philipp, G. Whiteman, Systems thinking: a review of sustainability management research, J. Clean. Prod. 148 (2017) 866-881, doi:10.1016/j.jclepro.2017.02.002.

[57] W.N. Adger, K. Brown, D.R. Nelson, F. Berkes, H. Eakin, C. Folke, K. Galvin, L. Gunderson, M. Goulden, K. O’Brien, J. Ruitenbeek, E.L. Tompkins, Resilience implications of policy responses to climate change, WIREs Clim Change 2 (2011) 757-766, doi: $10.1002 /$ wcc. 133.

[58] J. Lawrence, P. Blackett, N. Cradock-Henry, B.J. Nistor, Climate Change: The Cascade Effect, Deep South National Science Challenge, Wellington, N.Z., 2019. 